\title{
A procedure for point clouds matching from range-data and image-based systems
}

\author{
Andrea Angelini ${ }^{1}$, Damiano Portarena ${ }^{2}$ \\ ${ }^{1}$ Institute for the Technologies Applied to Cultural Heritage, CNR-ITABC, Via Salaria Km 29,300-00015 Monterotondo, Italy \\ ${ }^{2}$ University of Rome Tor Vergata, Via Columbia, 1, 00133 Rome, Italy
}

\begin{abstract}
Most of the survey techniques used in archaeology and architecture are focused on range-data (laser scanning) and image-based systems (digital photogrammetry). The paper aims to highlight a different methodological approach in the acquisition and processing procedures of the numerical data. The proposed methodology suggests an alternative way to match point clouds from laser scanner and image-based systems, exploiting the properties of the ICP algorithms. Some tests were performed at different scale in order to achieve the suitable procedure, evidencing the differences with the classic employed methods. The figures show this comparison and the making of the new procedure. The results are very interesting and concerned the merging of the numerical models from different sources. The correct position of the points in space aids the next step of the surface reconstruction (meshing process) and the final 2D representation.
\end{abstract}

\section{Section: RESEARCH PAPER}

Keywords: point clouds matching; ICP algorithms; numerical models; laser scanner; digital photogrammetry

Citation: Andrea Angelini, Damiano Portarena, A procedure for point clouds matching from range-data and image-based systems, Acta IMEKO, vol. 6, no. 3, article 9, September 2017, identifier: IMEKO-ACTA-06 (2017)-03-09

Section Editor: Sabrina Grassini, Politecnico di Torino, Italy

Received March 15, 2017; In final form July 18, 2017; Published September 2017

Copyright: () 2017 IMEKO. This is an open-access article distributed under the terms of the Creative Commons Attribution 3.0 License, which permits unrestricted use, distribution, and reproduction in any medium, provided the original author and source are credited

Funding: The methodological work is part of the research activity in the CNR

Corresponding author: Andrea Angelini, e-mail: andrea.angelini@itabc.cnr.it

\section{INTRODUCTION TO RANGE-DATA AND IMAGE-BASED SYSTEMS}

This research comes from the need to find accurate solutions in the survey discipline, currently subject to the technological development and the automated procedures. The paper concerns a research activity that investigates Survey issues through different instrumentations and software. Most of the survey techniques used in archaeology and architecture are focused on range-data (laser scanning) and image-based systems (digital photogrammetry).

Although the results being similar (point clouds), the two methods are based on completely different geometric principles. Laser scanning systems are based on the principle of "polar" acquisition. The instrument is able to collect an accurate and detailed amount of 3D information in a specific time, rotating 360 degrees around the vertical axis. The results are point clouds with 3D coordinates, the reflectance information and the RGB value (Figure 1) [1].
Image-based systems are based on the geometric principle of the space forward intersection. The system is able to collect 3D information of a subject using algorithms for the automatic recognition of the homologous points between two or more images (perspectives) [2]. Through this method it is possible to carry out point clouds similar to those of a laser scanner with colorimetric value associated, taken directly from the camera sensor (but without reflectance information, Figure 2).

The main difference between the two systems consists in the structure of the data [3]. Laser scanning systems are made up of structured data, included in a regular grid with known characteristics such as the exact number of rows and columns of the point clouds, the coordinate of the points, the reflectance information and the RGB value taken from a sensor built in the scanner (where provided). For each scan the projection centre is exactly known, recognized as the source of the laser beam. During a pre-processing step this characteristic allows to 


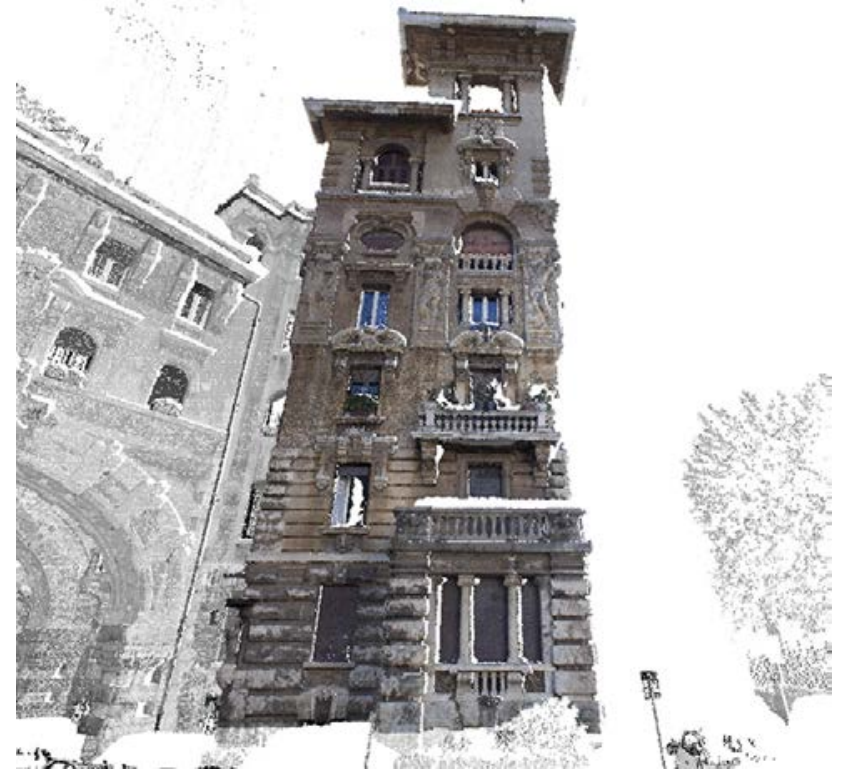

Figure 1. Point cloud from laser scanner of the main façade of an historical building in Rome, Palazzo degli Ambasciatori. The cloud presents different shadow areas generated from the position of the laser.

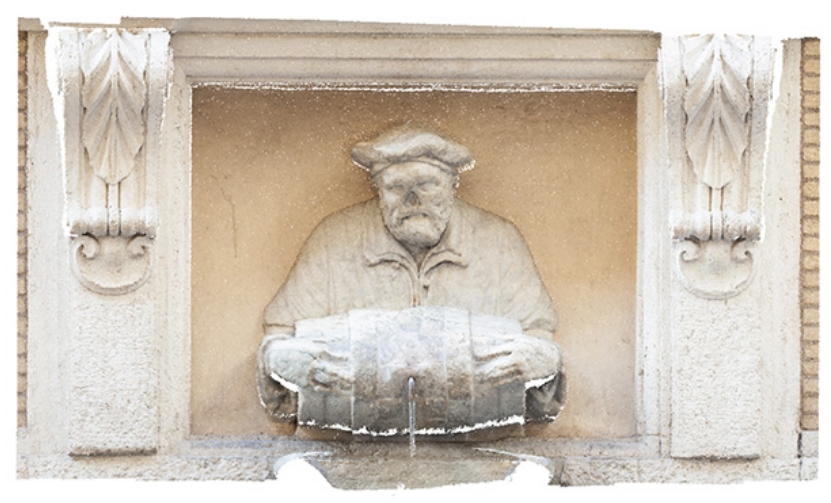

Figure 2. Point cloud of the Facchino's historical fountain in Rome generated with an image-based system. RGB values are taken directly from the camera sensor. The cloud is made up of unstructured data.

remove noise from the data and to add further information such as the orientation of the main planes (local tangent planes).

Image-based systems are made up of unstructured data, not included in a regular grid due to the different principle of the geometric reconstruction based on the epipolar geometry [4]. This particular geometry is able to establish a relation between a couple of images. Consider two different frames and a point $\mathrm{P}$ in the space. The point $\mathrm{P}$ generates two homologous projections on the corresponding frames. In order to create the adequate relation the corresponding images of the projection centres (epipoles or epipolar points) are defined on the frame. The epipolar plane is identified from the base and the collineation lines. The intersections between the epipolar plane and the two image planes are called epipolar lines. The image of the homologous point of the other frame lies on the epipolar lines.

The unstructured point cloud is characterized only from the coordinates of each point and the related RGB value. As known, the physical characteristics of the subject can influence the resolution and the uniformity of the results so that the points are irregularly distributed [5]. From the point cloud it is only possible to calculate the different position of each camera frame (external orientation) and not a single projection centre. Due to these characteristics no further information can be added.

The paper aims to highlight a different methodological approach in the investigation and processing procedures of the numerical data. The idea was to study different methods of data acquisition and integration between laser scanner and digital photogrammetry, comparing the final results performed through the innovative procedure.

The survey pipeline can be divided in four main steps [6]:

- The acquisition of the subject;

- The processing of the numerical model;

- The reconstruction of the surfaces (mesh);

- The bi-dimensional (2D) representation;

The experimentation was focused on the first two steps of the pipeline (acquisition and processing). These two phases evidence some questions that often are not considered during a survey and that are important for the final representation and the accuracy of the project. Most of the projects are currently based on the integration among different survey techniques to reach a deep knowledge of a subject and a complete numerical model for further processing.

The question is whether we are able to properly combine data from a laser scanner and digital photogammetry in a survey project and which is the right procedure for performing the best results. The idea was to systematize the "virtual matching" between the point clouds in order to define a different and rigorous procedure useful for the archaeologist and architects.

\section{THE INTEGRATED SURVEY}

Until few years ago survey methods (in archaeology and architecture) were usually based on the integration between laser scanner (Time Of Flight, Phase-Based) and topographic systems (total station and/or Global Navigation Satellite Systems). With the aid of a total station, closed traverses were performed in order to register the scans of a survey project and to decrease the spread error of each scan of the laser. The entire scan project was registered through the use of planar targets (more recently spherical targets), the Ground Control Points (GCPs; Figure 3) [7], [8]. Precisely each single scan of the laser behaves

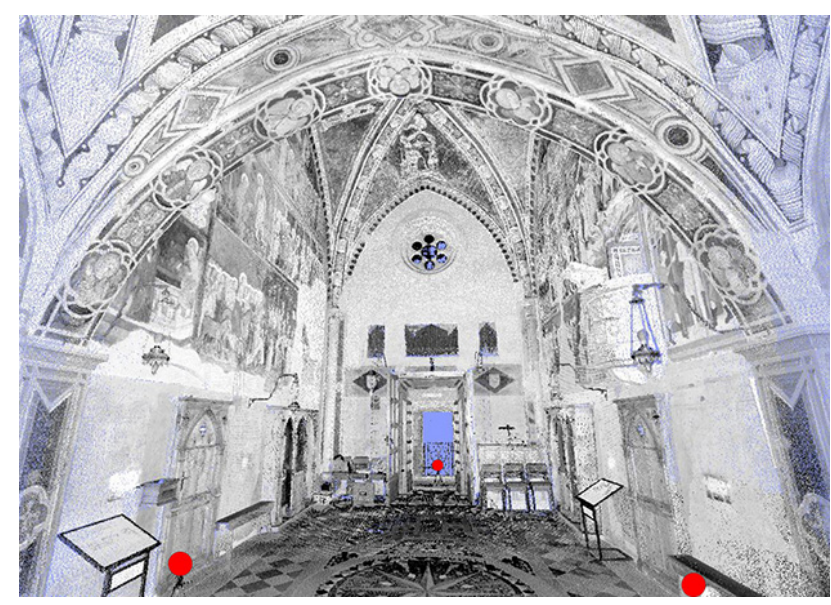

Figure 3. The scans registration phase was usually conducted through planar and/or spherical targets. Planar GCPs are often related to a topographical survey. 
like the main nodes of a total station, due to the same principle of acquisition (polar), indeed the difference consists only in the number of collected points. In topography each node of the closed traverse suffers from a spread error that must be compensated with known formula (angular and distance compensation). The approach with the GCPs allowed to reduce the mutual position of the scans in the reference system, controlling the registration error of the final survey [9].

Recently a series of algorithms for the correct mutual position of the scans have been implemented (C2C Registration). Such algorithms are known as Iterative Closest Points (ICPs) [10], [11].

Despite they have been already developed in the 90's, different implementations have made them common for the software of $3 \mathrm{D}$ point clouds managements. Since their developing many variants have been implemented in these years in the different phases of the algorithms but this part is not included in the paper. After a pre-registration step, performed manually, ICPs are able to move a point cloud over another point cloud (the reference one) on the basis of thousands of points (from 5.000 to 20.000 and over), thus reducing the final overlapping error. The ICP algorithm works with laser scanner data and, where present, the GUI (Graphic User Interface) is composed by different values that can be changed by the user (Figure 4).

In order to satisfy the algorithm two structured scans have to be pre-registered manually on the basis of 3 or more points. The mutual starting distance between the scans can influence the quality of alignment and the number of iterations. Most of the software for point clouds management employs the ICP tool with different characteristics (Figure 5).

This approach allowed to change completely the procedure during the acquisition step. At present, it is more important to have a good overlap $(60 \%)$ among the subsequent point clouds in order to satisfy the requirements of the ICP algorithms. The ICP registration allows to reduce the spread error up to a few millimetres, effectively excluding the topographical survey (the use of topography depends also on the case study, considering the extension and complexity of a building). The risk is that the acquisition of the GCPs with a total station would increase the registration error among the scans.

In this way the topographical approach could be used only

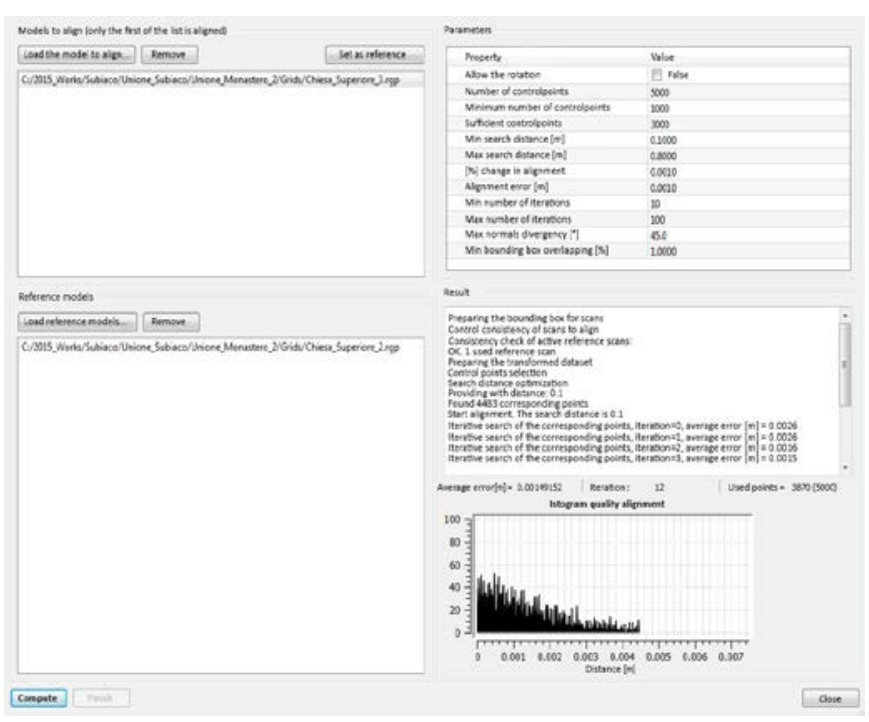

Figure 4. Usual ICP algorithm interface. Different values can be set up by the user in order to register correctly two scans.

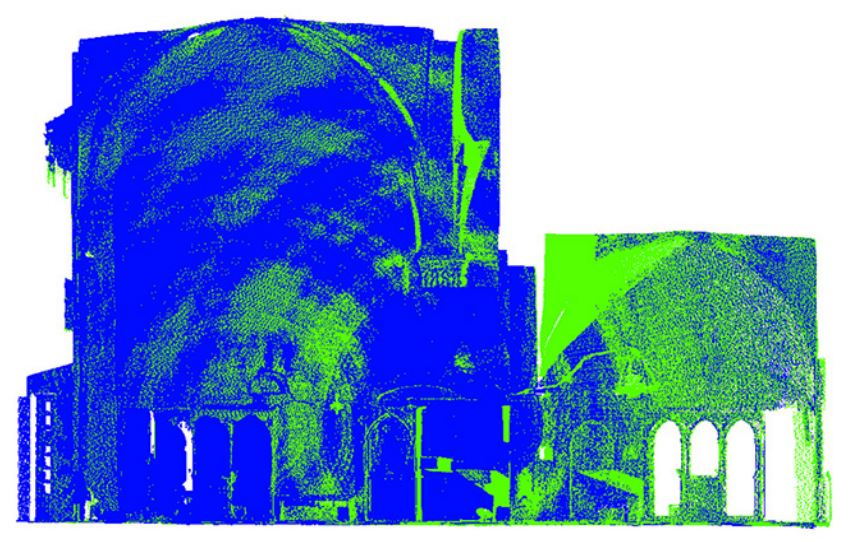

Figure 5. The result after a fine registration Cloud to Cloud (C2C). Sometime the quality of alignment can be reduced below the millimetre.

for georeferencing different scan projects in the same reference system.

The next step consists in the bundle adjustment step, a further processing that redistributes the remaining errors among the entire scan project.

\section{THE ALTERNATIVE PROCEDURE}

One of the main issues of the processing step concerned the matching of two point clouds from different data sources (laser scanning and digital photogrammetry) within a same reference system (local or global). The idea was to reconstruct a numerical model that was the result of acquisitions performed with different techniques, maintaining a final good quality.

For that reason an alternative procedure that integrated the two data sets has been developed, exploiting the properties of ICP algorithms. For the experimentation point clouds were used instead of surfaces (mesh), considering the surface reconstruction as an interpolation that could modify the position of the points [12]. The resolution and the accuracy of the point clouds depend on the intrinsic characteristics of the instrument used (laser or camera), the environmental situation, the position of the instruments in a survey project and the acquisition method used [13]. Furthermore for the image-based system it is essential to apply a proper data capture by using two possible different methods for avoiding incorrect results (convergent or parallel acquisition).

As known, data from image-based systems are not scaled (when they are not stereoscopic) and the referencing step can be performed on the basis of some points picked directly on the point clouds of the laser scanner or with the aid of a total station. This procedure allows to scale the unstructured model and reference the clouds in the same coordinate system. The positioning error depends on many factors such as the choice of the points (the geometric disposition) and the different resolution of the two compared numerical models (Figure 6). Same points can be described with a different number of pixels. Despite the error appears to be low in the chosen points, in other areas the overlap may be incorrect. This evaluation can be displayed by the mean squared error and comparing the absolute distance between the two clouds.

The pipeline of the suggested procedure is shown below:

- Range data (laser scanner) acquisition of a subject;

- Image-based data (digital photogrammetry) acquisition of the same subject from different points of view for integrating the shadow areas; 


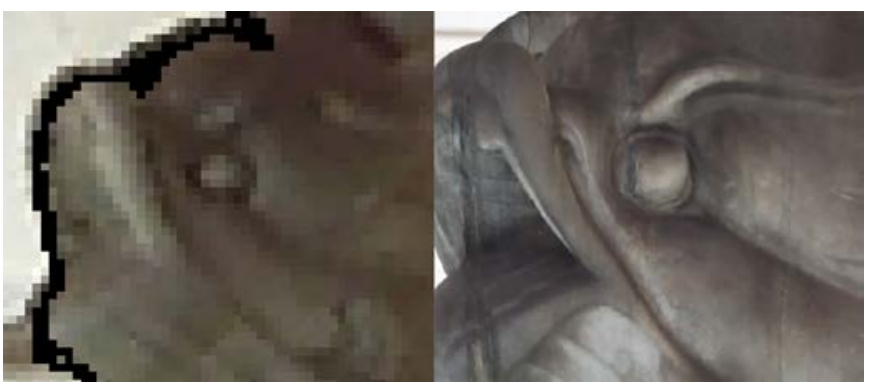

Figure 6 . The positioning error of the points depends mainly on the different resolution of the clouds. The eye of the mythological dolphin is represented with more pixels in the image-based acquisition (right) than the laser scanner (left).

- Scaling of the image-based system using reference points of the laser scanner, evaluating the general registration error (MSE);

Transformation of unstructured data (digital photogrammetry) into structured data through the Vitual Scan tool;

- Fine Registration Cloud to Cloud (ICPs);

- Evaluation of the error comparing the absolute distance with the numerical model of the laser before and after the procedure;

- Surface reconstruction (mesh process);

- Generation of different 2D representations.

The acquisition is the first step of the pipeline. The Laser was set up for recognising data at high quality, maintaining a 60 $\%$ of overlap among the scans.

In order to have defined images and a good field depth the camera settings were modified by using automatic shutter, diaphragms at f11/f14, ISO sensibility at 100 and infinity focusing.

As mentioned above in order to match the two data sets, points of the laser scanner were used to scale the model of digital photogrammetry. The accuracy of the transformation depended on the number of points taken, on their geometric disposition on the model and the adequate registration in the same position [14]. This part of the classic employed process is without doubt correct but differences in overlapping can be evidenced comparing the two clouds. These errors depend probably on the dimension of the subject and they can influence the step of the surface reconstruction (meshing process).

The innovation of the procedure consisted in the application of ICP algorithms between two different data sources for the correct matching of the point clouds. In order to accomplish this process unstructured data (image-based) were transformed into structured data such as the laser scanner. This transformation was carried out through a simple tool known as Virtual Scan, developed by Gexcel (JRC Reconstructor) [3], [15].

This tool allows to make a virtual scan of a subject in the virtual space. Once an orthographic camera that includes the numerical model is established, the whole point cloud can be acquired at a specific resolution, such as a laser scanner. At the same time a spherical or a cylindrical camera can be created in any virtual position, simulating the same movement of a panorama scanner (Figure 7). For instance, by using the spherical camera, the tool allows to register a real equirectangular grid $(360 \times 180)$ composed by digital photogrammetric points without altering their position (a graphic card assembled on the computer can influence the resolution and reduce the processing time).

In this way it is possible to create a new structured 3D numerical model of the subject with the same characteristics of a point cloud taken with a laser scanner in any virtual position. The new structured model contains fewer points than the original, but the main advantage consists in the possibility to apply the pre-processing algorithms to photogrammetric data (noise reduction, local tangent plane and the orientation discontinuity).

This particular process gives the same characteristics of the laser scanner to the (unstructured) point cloud, necessary for the ICP data registration. Knowing the exact projection centre of the new cloud (spherical, cylindrical or "orthographic") software is able to pre-process data also conferring new information such as the orientation of the local tangent planes. After a manual alignment between the two scans, the fine registration can be performed with the ICP algorithms that will find the best position between the two point clouds. The algorithm finds the best position calculating the final error, iterating the process different times and roto-translating the mobile cloud over the reference one.

The next step consisted in the evaluation of the overlapping error by measuring the distance between the two clouds before and after the ICP registration. Cloud Compare software was used to inspect the distance and evaluate the results. Different maps have been created in order to compare the numerical models and appreciate the final error (laser scanner model, digital photogrammetry model, ICP digital photogrammetry model).

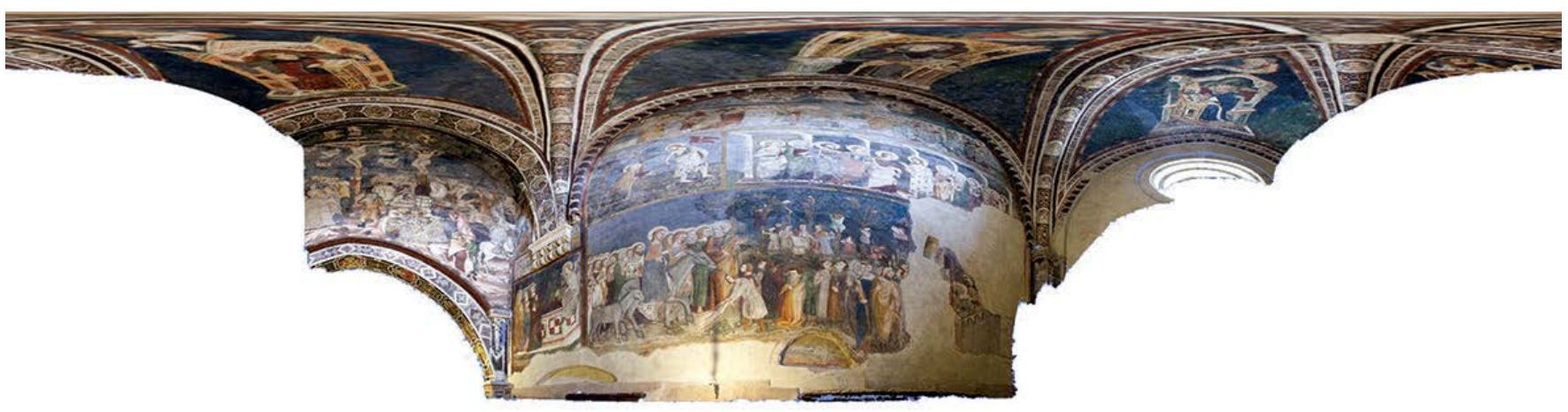

Figure 7. Virtual Scan of the image-based acquisition from a spherical camera positioned in the same projection centre of the laser scanner and with a $3600 \times 1800$ resolution grid, Monastery of Subiaco. 


\section{THE EXPERIMENTATIONS}

The experimentations were carried out on different subjects, at different scale, in order to verify the suitable procedure. The acquisition was performed with a phase based laser scanner Faro 120 (distance accuracy up to $\pm 2 \mathrm{~mm}$ at $130 \mathrm{~m}$ ) and with a Canon Eos 5D Mark II, with 28/50 mm fixed optic lens.

The survey concerned two historical fountains in Rome (The Facchino's Fountain, The Fountain of Piazza Nicosia), the first span of the Upper Church of the Benedictine Monastery of Subiaco, the main front of an historical building in the Coppedè district (Palarzi degli Ambasciatori, Rome), and the main façade of the Palace Tomb in Petra.

\subsection{The Facchino's Fountain in Rome}

Facchino's Fountain represents a little monument preserved in Rome useful for the analysis of freeform surfaces. The face and the chest of the sculpture are very articulated and partially damaged. Two scans at very high resolution (indoor $20 \mathrm{~m}$, laser beam iteration $4 \times$ ) were performed and about 10 images from a tripod were shot ( $2 \mathrm{~m}$ from the statue). For the face additional images were taken closer to the statue. The numerical model of the laser was composed by 10 million of points while the numerical model of the image-based system was composed by 11 million of points. With the classical method the mean squared error of the projected points from the laser was 0.0035 $\mathrm{m}$. Despite the small error, after the Virtual Scan transformation the ICP procedure was able to further reduce the value to $0.0015 \mathrm{~m}$. Comparing the clouds different distribution of the error can be noticed before the ICP registration and after (Figure 8). Blue colour evidences the exact correspondence of the clouds while green colour evidences a
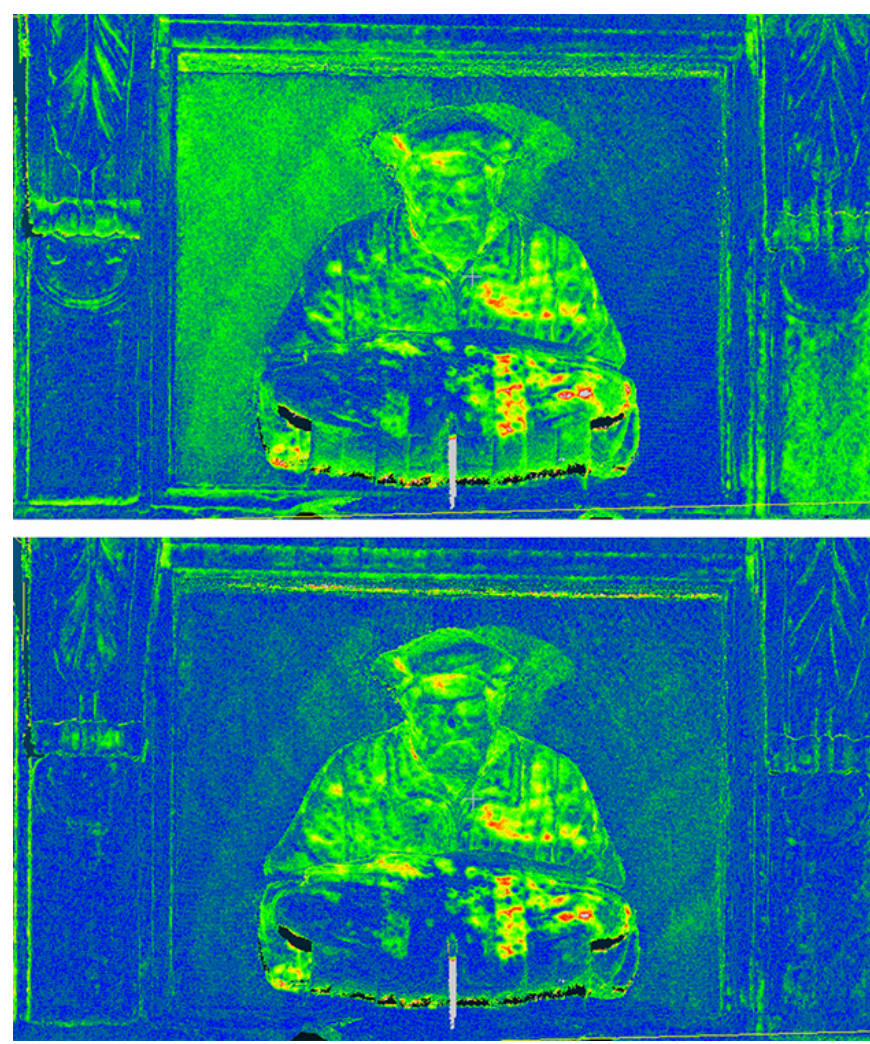

Figure 8. The images show the distance between the clouds before and after the application of the ICP algorithm. Blue colour evidences the exact correspondence of the clouds while green colour evidences a major distance between the clouds included in a threshold of $0.007 \mathrm{~m}$ major distance between the clouds included in a threshold of $0.007 \mathrm{~m}$. The figure shows also the best fitting of the clouds where the green colour is well distributed on the sculpture maintaining the constant error.

The next figure (Figure 9) shows the histograms of the approximate distances of the points between the analyzed clouds with the "classic" georeferencing mode and after the ICP processing. The ICP approach reduces considerably the distance among the points, moving them in the first 2 classes of the table (Class 1 between $0 \mathrm{~m}$ and $0.0008 \mathrm{~m}$ - Class 20.0008 $\mathrm{m}$ and $0.0016 \mathrm{~m})$.

Independently from the applied procedure (classical or innovative) a mismatching between the clouds can be noticed (mainly on the sculpture) and it depends on the reconstruction algorithm (Structure from Motion) of the photo-scanning system related to the laser scanner [16].

Another experimentation was made with a stereoscopic system, using only 3 images. Stereoscopy is a very useful technique to scale the object without any other measurement. The known distance between the three cameras and the distance from the subject allows to have metric information. The accuracy depends on the relation between the distance from the subject and the mutual distance of the three cameras. In this case, with a baseline of $200 \mathrm{~mm}$ and a distance from the

\section{Approximate distances classic georeferencing mode}

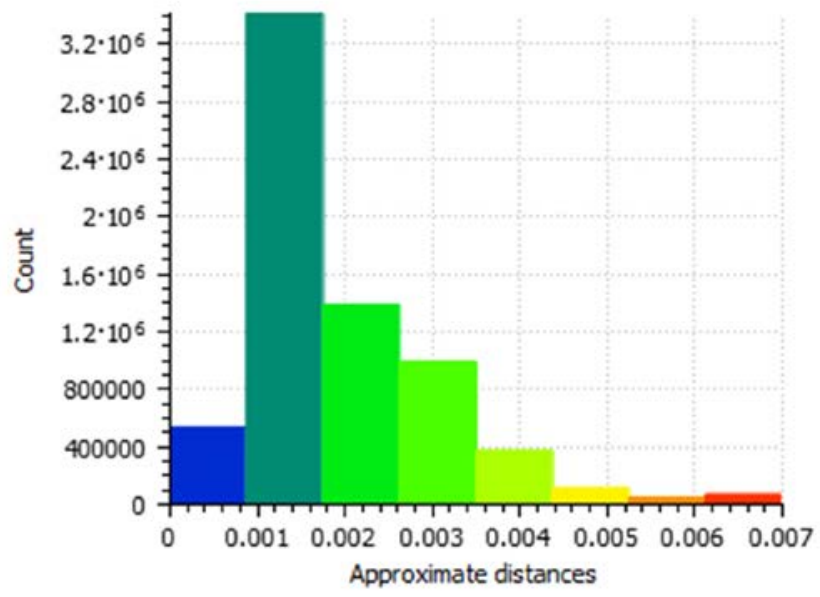

Approximate distances ICP transformation

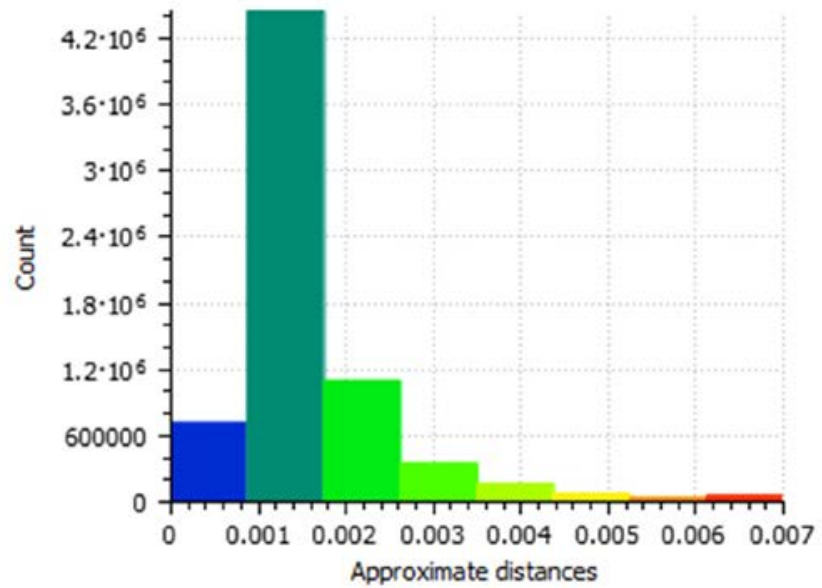

Figure 9. The figure shows the approximate distance between the clouds before and after the ICP procedure. The use of Virtual Scan allows to reduce considerably the distance among the points. 
statue of $1.5 \mathrm{~m}$, declared accuracy of the numerical model was between $0.41 \mathrm{~mm}$ and $1.64 \mathrm{~mm}$ [17], [18]. The point cloud was composed by 1.5 million points and the GCPs from the scanner were used only for georeferencing the model in the same local system to view the differences. The starting error between the two models was $0.005 \mathrm{~m}$. The numerical models were aligned cloud to cloud through ICP algorithms to improve the correct position of the photogrammetric model. Most of the points are aligned with an error of $0.001 \mathrm{~m}$. Despite the stereoscopic system gives information about the accuracy of the numerical model, the result seems less accurate than the multi-stereo model.

\subsection{The Fountain of Piazza Nicosia in Rome}

The fountain represents an example of a round subject, useful to check how the algorithm behaves in different conditions, considering the complexity of the shapes characterized by 4 symmetric mythological dolphins.

As in the previous example a scan project was organized in order to acquire the whole historical subject [19]. The regular geometry of the fountain allowed to position 8 scans at high resolution (indoor $10 \mathrm{~m}$, laser beam iteration $4 \times$ ). The 8 scans were merged into a single point cloud due to the shape of the baluster and to have a complete subject. The merging process among different structured scans generated a new unstructured point cloud with the same characteristics mentioned in Section 2. To avoid the problems of unstructured data, the numerical model was turned into structured data using a virtual cylindrical camera with the main axis positioned in the centre of the baluster and with a height of $1 \mathrm{~m}$. The virtual scan produced a new grid cloud composed by 7.2 million points as the result of the imposed resolution $(7200 \times 1000)$. The new point cloud was used as the reference model in the distance evaluation.

Simultaneously, a photogrammetric project was arranged on the central baluster of the fountain using 20 images with a $50 \mathrm{~mm}$ optic lens. The numerical model of the image-based system was composed of 7 million points.

5 GCPs on the entire surface were identified in order to overlay adequately the two models and with a projection error of $0.001 \mathrm{~m}$ (Figure 10). The cylindrical virtual camera (the same as the laser) was used to transform image-based data into a structured model.

The ICP procedure was able to further reduce the accuracy value down to $0.0008 \mathrm{~m}$.

The figure shows the result before and after the ICP
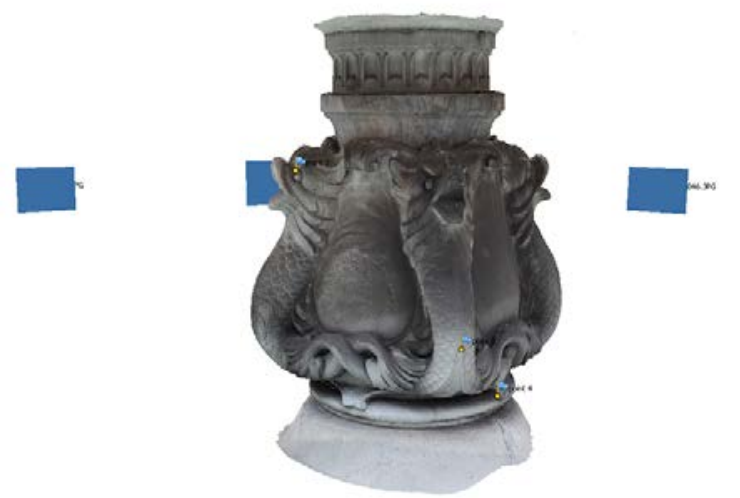

Figure 10. Image-based project of the central baluster of the fountain. Characterized by 4 mythological dolphins the pattern of the marble allowed to pick at least 5 GCPs. algorithm application (Figure 11). In order to compare the differences on the tests and to have a planar projection, the numerical models were unrolled on the $\mathrm{z}$ axis and with the ratio of 1. Although most of the points are in the threshold, prior defined in $0.01 \mathrm{~m}$, in the first processing the points are irregularly distributed over the surface $(0$ is blue and 0.01 is red); some areas of the baluster match better than other, in particular some problems occurred in the shape of the mythological dolphins. In the second data processing (ICP model) the average distance was reduced $(0.0008 \mathrm{~m})$ and the points are well distributed on the entire sculpture.

Cylindrical projection allowed to get a single grid model useful for the evaluation of the entire surface of the historical fountain, but the main problem consisted in the impossibility to view the shadows of the subject already surveyed due to the infinity direction of the projecting rays. For that reason the numerical model of the laser should be used only to match correctly the position of the baluster in the entire fountain and eventually replaced with the ICP image-based model.

\subsection{The Benedictine Monastery of Subiaco}

The third experimentation concerned the first span of the Upper Church of the Benedictine Monastery of Subiaco. The application was performed for an interior subject characterized by a complex architecture. In particular the example was used to visualize the correspondence for the cross vault, positioned at $7 \mathrm{~m}$ from the ground, in order to analyze one of the most important cases of an unfinished vault in the history of the Architecture.

The numerical model of the laser was composed by 25 million points, while the numerical model of the image-based system was composed of 17 million points. The referencing step was aided by the presence of the painted frescoes. In particular, the eyes of the characters of the holy representations have been the reference points between the two different numerical models. 16 points were used to reference the imagebased model on the laser with a projection error of $0.0035 \mathrm{~m}$. Despite the low error the absolute distance evidenced a different position of the two models. Once established a threshold of $0.01 \mathrm{~m}$, differences emerged in the position of the rib vaults. Being an interior space the data of the image-based

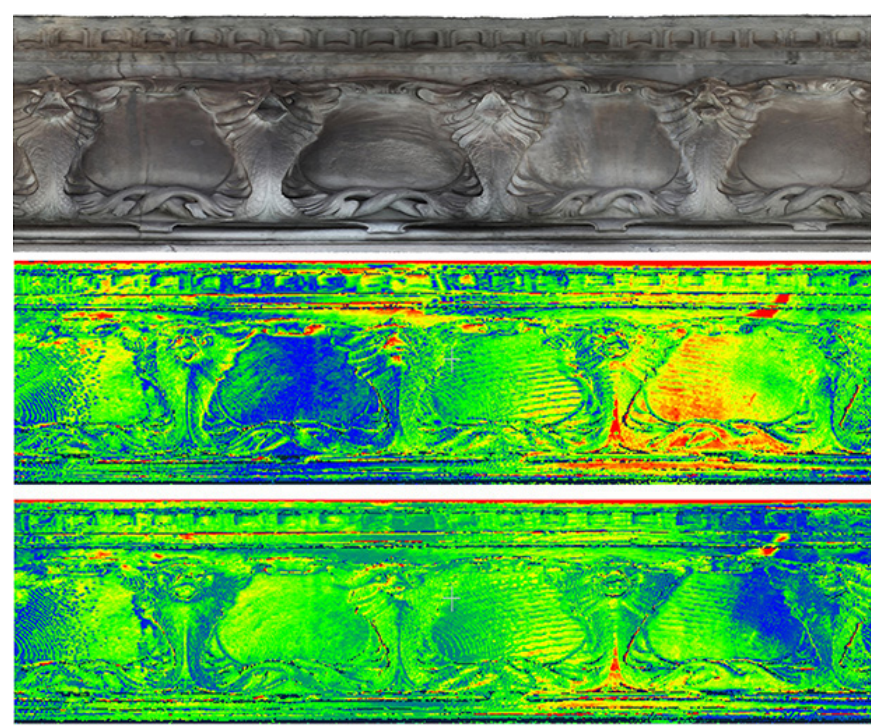

Figure 11. Planar development of the central baluster of the fountain with the processing of the distance between the models, before and after the ICP algorithm application. 
system were transformed to structured data from the same projection centre of the laser, using a spherical camera to acquire the same data window [20].

The resolution was set up at $3600 \times 1800$ and the result was a point cloud of 6.5 million, lower than the original (Figure 12). The ICP algorithm reduced the error down to $0.0029 \mathrm{~m}$ with an homogeneous distribution of the points, useful for data integration (Figure 13). For this example the overlapping error has been also evidenced through the representation of cross sections. The black outline represents the section generated from the laser scanner, the red one represents the image-based model referenced with the laser, the green section shows the performance of the ICP algorithm applied to digital photogrammetry. On the Cartesian plane the final error decreased to about $0.01 \mathrm{~m}$. In this representation distances among different parts of the numerical model can be exactly measured. The reduced error between the clouds aided the surface reconstruction process of the cross vault, studied and

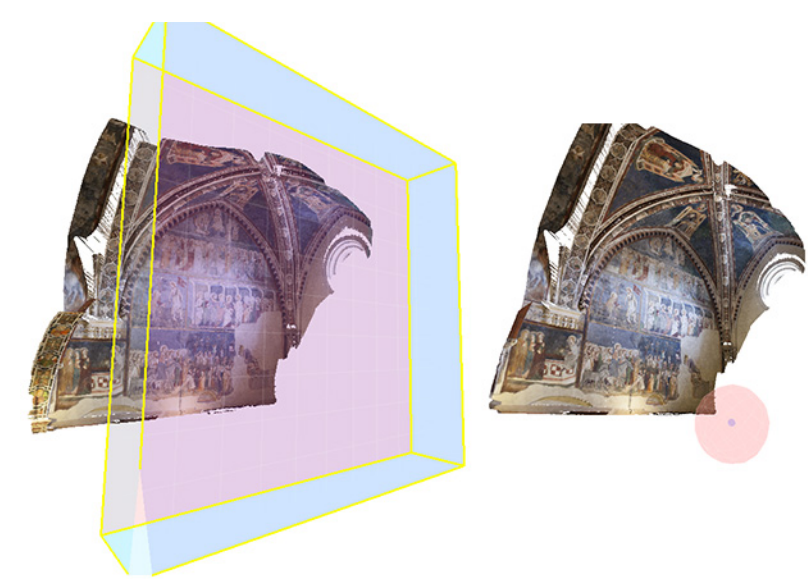

Figure 12. The image shows two different options of the Virtual Scan. On the left the orthographic camera, on the right the spherical camera.
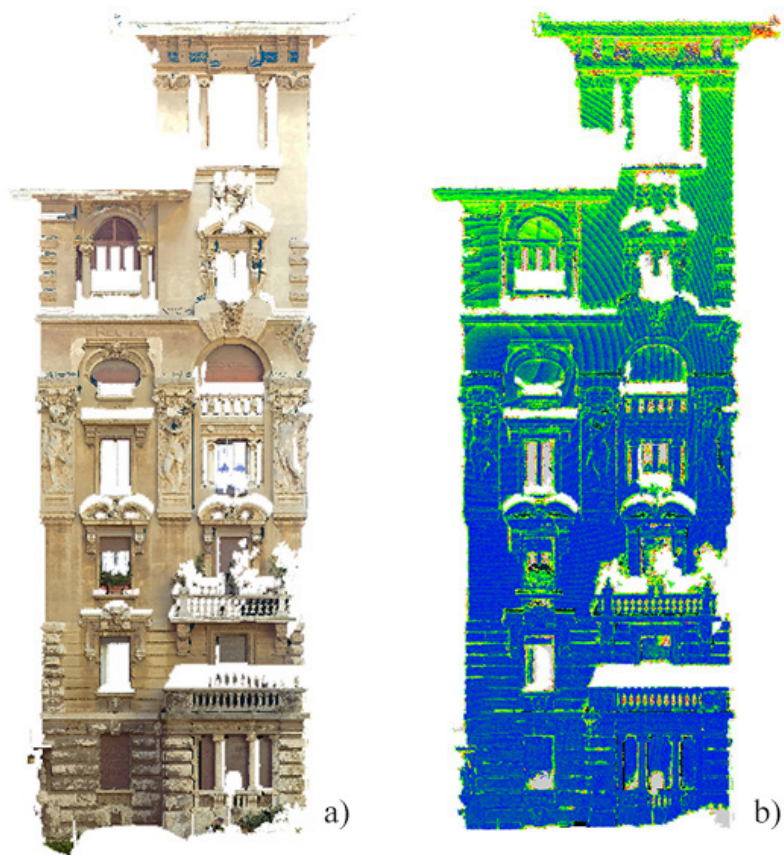

b)
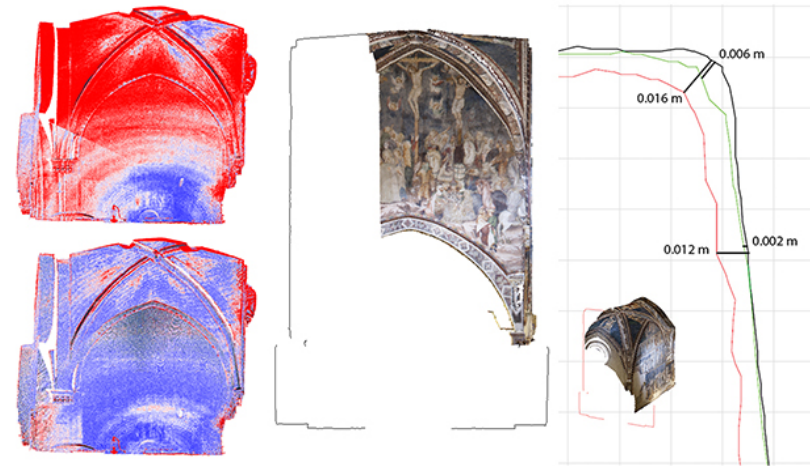

Figure 13. The image represents the absolute distance between the two models in a threshold of $0.01 \mathrm{~m}$. Blue colour evidences the coincidence of the models while the red colour the maximum gap. The representation has been also projected in the Cartesian plan.

analyzed though the innovative procedure.

\subsection{Palazzo degli Ambasciatori in Rome}

Another case study was carried out on the main façade of Palazzo degli Ambasciatori, the most representative building of the Coppedè district in Rome. It consists of three separate units combined in two triangular wings connected by a large arch, representing a triumphal entry.

The work focused on the south tower of the palace considering the height and the complex style used for its appearance. In this case only one scan has been used (outdoor $20 \mathrm{~m}$ and over, laser beam iteration $4 \times$ ) and 30 images taken from the camera.

The laser model was composed by 6 million points while the image-based model by 53 million points. As in the other cases the ICP procedure was applied to correct the positioning error derived from the manual referencing have been generated (Figure 14). The first one is based on the spherical projection centre, the second is based on the orthographic camera

Figure 14. The numerical models have been compared to evaluate the distance among the points with spherical and orthographic projections: a) laser scanner model; b) distance between laser and photogrammetry models through the classical georeferencing approach; c) distance between laser and photogrammetry models through the ICP approach (spherical camera); d) distance between laser and photogrammetry models through the ICP approach (orthographic camera). 
characterized by a projection centre focused to infinity. The comparison among the three different numerical models points out some important aspects.

The starting mean squared error of the projected points from the laser on the unstructured model was $0.015 \mathrm{~m}$. Although the error may be accepted, the ICP transformation further reduced the value down to $0.012 \mathrm{~m}$ (spherical camera) and $0.007 \mathrm{~m}$ (orthographic camera). Some consideration can be made on the starting projection error between the two models. Even if the MSE is not as high, the most overlapping error is visible in the upper part of the façade, considering the height of the south tower $(20 \mathrm{~m})$. The laser maintained the same accuracy for this distance while camera acquisitions were made from the main street and the greater distance of the subject in the upper floors decreased the resolution and the accuracy of the model Although 9 markers were used for referencing the two models, the difference compared in the software (Cloud Compare) evidenced a gap of $1.5 \mathrm{~cm}$ in the upper floors of the palace (Figure 14b).

Using the spherical acquisition from the same projection centre of the laser, the average distance can be reduced down to $3 \mathrm{~mm}$ and homogeneously distributed over the entire surface of the palace. However some area presented green values $(1.2 \mathrm{~cm}$ and over), in particular on the sculptures that characterize each single floor.

The expedient of the orthographic camera allowed to acquire data with a projection centre with infinite direction. The orthographic approach reduced considerably the overlapping error on the façade (below a millimetre).

\subsection{The Palace Tomb in Petra}

The last example concerned the monumental Palace Tomb in Petra, within the project "The ancient drainage system of Petra: analysis and restoration for cultural heritage conservation. Methodologies applied to the conservation of the monumental Palace Tomb" led by dr. Gabrielli of CNR [21]. The tomb represented one of the most important rock-hewn architectures in the antiquity. Both carved in the lower part and built in the upper part, the façade is characterized by 5 different orders inspired by the Hellenistic palaces in the Roman Empire and the height of the monument is greater than $45 \mathrm{~m}$ [22]. Since 1976 some photogrammetric projects were carried out in the area in order to study the archaeological features and the degradation of the sandstone on the surfaces [23].

Different acquisitions were performed on the Tomb in order to analyze data about the integration between laser and photogrammetry for accomplishing the surface reconstruction of the tomb and solving the problem of the shadow areas. An acquisition was provided with the laser scanner from the podium of the Royal Tomb (outdoor over $20 \mathrm{~m}$ ). The photogrammetric project was made with the aid of an air gas balloon and a reflex camera positioned 10 meter from the façade. More than 300 images were taken at different heights and processed with $S f M$ (Structure from Motion) systems (Figure 15).

The numerical model of the scan (from the centre of the tomb) was made up of 9 million points while the unstructured cloud of the image-based project was made up of 24 million points.

As in the other cases the procedure was applied to correct the positioning error of the photogrammetric cloud over the laser data. 10 GCPs were picked from the model of the laser for georeferencing the unstructured cloud. The starting MSE of the project was $0.082 \mathrm{~m}$. Different tests were performed to change this value picking different points but the dimension of the monument conditioned the quality of the projection. The error cannot be accepted considering the common representation scale of the monument $(1: 50,1: 100)$. The theoretical graphic error may be a maximum of $1.5 \mathrm{~cm}$ for $1: 50$ representation scale [24]. Virtual Scan was used to transform the unstructured cloud and correct the matching error of the models. Virtual scan (orthographic camera) was performed considering the photogrammetric acquisition, made with a gas balloon, that covered the entire surface. The model was completely rescanned with a resolution grid of $2616 \times 2980$, producing a new point clouds of 8 million points, similar to the cloud of the scan and simple to manage with ICP algorithms. The ICP application decreased the general error down to $0.012 \mathrm{~m}$ with a good distribution over the entire surface (Figure 16). The figure

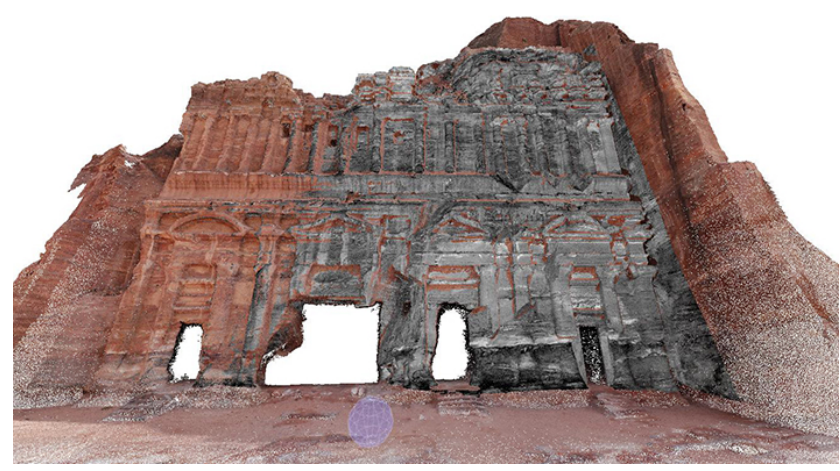

Figure 15. Starting position of the two numerical models evidences the mismatching between the clouds.
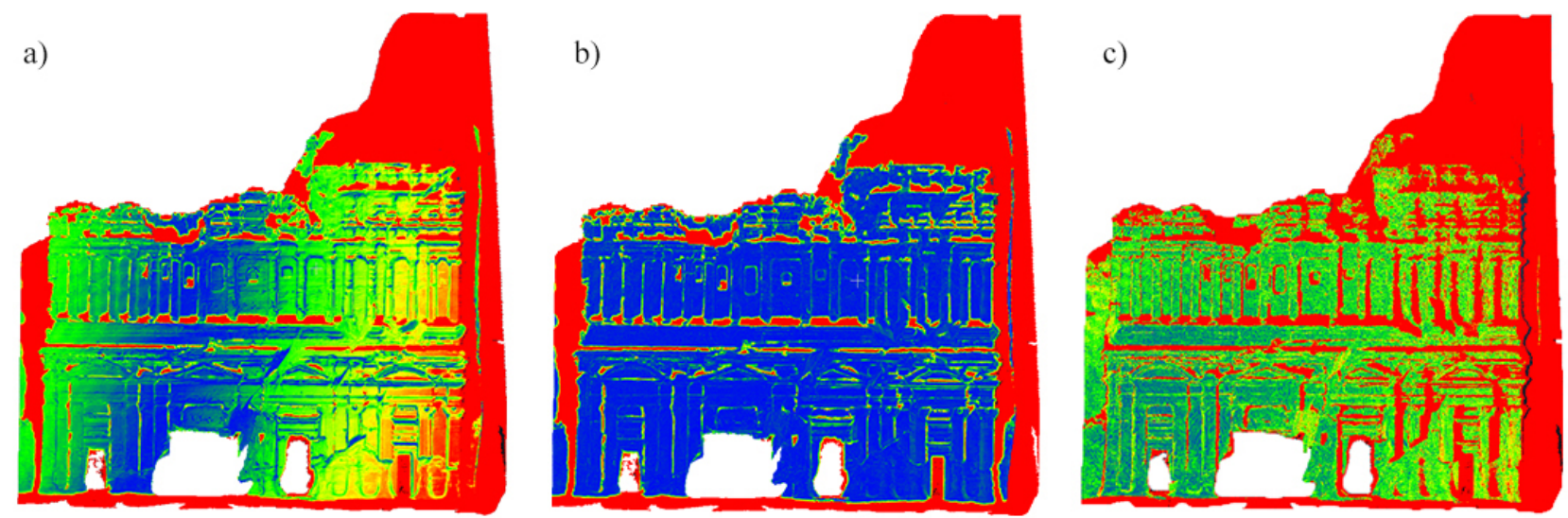

Figure 16. The application of the ICPs algorithms reduced the distance among the clouds integrating correctly data from different sources. 
evidences the distance between the two models in different condition. In the first two images $(\mathrm{a}, \mathrm{b})$ the threshold was set up at $0.30 \mathrm{~m}$, in order to highlight the different position of the models before and after the ICP application. Same colours can evidence, at the same time, positive or negative values. In the first processing (a) the only coincident part between the models is represented by the blue value. After the ICP process and maintaining the same threshold, the model appeared coincident on the entire surface (b). Decreasing the threshold at $0.05 \mathrm{~m}$ the average distance of the points is below $1.5 \mathrm{~cm}$, inside the accepted graphic error for the $2 \mathrm{D}$ representation of the tomb. Red areas represent the integrated part of the shadow areas in the correct position.

\section{CONCLUSION}

Some considerations can be made as the conclusion of the paper. The presented research must be considered as a different interpretation of the processing phase of the survey pipeline and not the only solution. The analyzed procedure highlights a method for understanding and solving some questions around data integration in the survey.

The integration between laser scanning and digital photogrammetry represents a method of study important for accomplishing the documentation and the knowledge of an archaeological subject. However, it is equally important to find a correct procedure for matching data together. Both the techniques are currently very useful in the field concerning the Cultural Heritage. The laser scanner maintains the accuracy independently from the adopted resolution (set up for the different dimension and context), but the limit concerns the impossibility to survey the shadow areas of an architecture.

Digital photogrammetry is able to survey all the subjects but the quality depends mainly on the sensor, the optic lens used and the distance from the subject. These parameters can affect the results of an acquisition considering, for instance, the dimension of a monument.

The presented tests showed how the average error between the clouds depends on the referencing mode and the dimension of the surveyed subject. The transformation with the Virtual Scan together with the ICP procedure reduced considerably this distance making the two clouds more homogeneous. The applied procedure does not modify the geometry of the clouds but it moves the mobile cloud on the reference one comparing the distance among points. It is not possible to reach the coincidence between the clouds considering the errors in the measurements and the intrinsic errors of the instruments (systematic errors that cannot eliminated and are independent from the used procedure).

The main advantages of the procedure are the correct integration between two different data sources (unstructured and structured data) but above all the possibility of an accurate surface reconstruction (Figure 17). The reduced distance of the points and their correct position aids algorithms for the meshing process and the entire interpretation of the data.

The integration of the two techniques allows to have the correct position of the object in space, a complete geometry and a defined morphology without shadow areas. Differences can be noticed in the figure below with the representation of the mythological dolphins ( $2^{\text {nd }}$ case study). The first image on the left represents the surface model generated from the laser scanner data, the central image the complete model generated through the integration of the digital photogrammetry after the Virtual Scan transformation and the ICP procedure. On this model it is possible to visualize the clear profile and the characteristics of the dolphins such as the scales. The last image concerns the application of the texture on the model for the final representation.

The consequence in archaeology and architecture consists in the possibility to generate the proper reconstruction of a monument starting from heterogeneous data and using a rigid method for the registration of the clouds.

The virtual scan is a suitable tool able to give useful information about the quality of the data and their position.

Future developments will concern the possibility to apply the method for integrating data between terrestrial laser scanner and image-based data from drones in order to verify the accuracy of the procedure at urban scale.

\section{ACKNOWLEDGEMENTS}

The paper is the result of the collaboration between the authors. In particular, for what concerns the national case studies, they are sincerely thankful to the technical assistance of
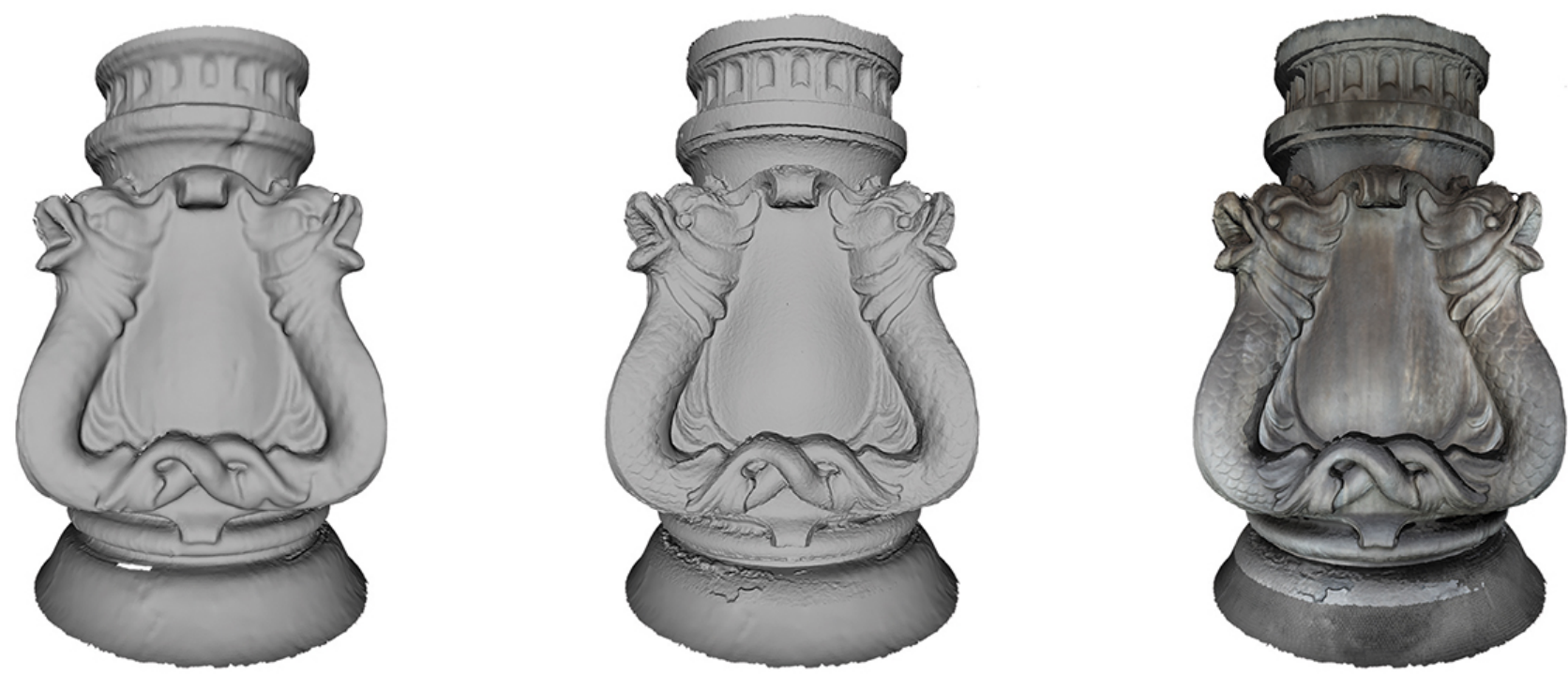

Figure 17. Surface reconstruction of the central baluster of the fountain with the integration between laser scanner and digital photogrammetry. 
Mr. Andrea Zavagnini for the experience showed during the acquisition and processing phases of the research.

\section{REFERENCES}

[1] G. Vosselman, H. G. Maas, Airborne and Terrestrial Laser Scanning, Whittles, Caithness, UK, 2010, ISBN 978-1904445-876.

[2] F. Remondino, M.G. Spera, E. Nocerino, F. Menna, F. Nex, "State of the art in high density image matching", in The Photogrammetric Record, Vol. 29, Issue 146, June 2014, pp. 144-166.

[3] M. Sgrenzaroli, G.P.M. Vassena, Tecniche di rilevamento tridimensionale tramite laser scanner. Volume 1 - Introduzione generale, Starrylink Editrice, Brescia, 2007, ISBN 978-88-8972073-8.

[4] M. Carpiceci, Modelli geometrici e costruzioni grafiche per il rilevamento architettonico. Idee e proposte per una migliore gestione dei dati grafici e numerici nel rilevamento architettonico, Aracne, Roma 2012, ISBN 978-88-548-5153-5.

[5] F. Remondino, S. El-Hakim, "Image Based 3D Modelling: a review", in The Photogrammetric Record, Vol. 21, Issue 115, August 2006, pp. 269-291.

[6] C. Bianchini, Documentation of Mediterranean ancient theatres. Athena's activities in Mérida, Gangemi Editore, Roma, 2012, ISBN 978-88-492-2524-2

[7] A. Angelini, R. Gabrielli, "Laser scanning e photoscanning. Tecniche di rilevamento per la documentazione 3D di beni Architettonici ed Archeologici", in Archeologia e Calcolatori, 24, (2013), ISBN 978-88-7814-580-1, pp. 374-394.

[8] H. Sternberg, "Deformation measurements at historical buildings with the help of three-dimensional recording methods and two-dimensional surface evaluations" IAPRS Volume XXXVI, Part 5, Dresden, 2006, pp. 303-308.

[9] M. Carpiceci, Modelli geometrici e costruzioni grafiche per il rilevamento architettonico. Idee e proposte per una migliore gestione dei dati grafici e numerici nel rilevamento architettonico, Aracne, Roma 2012, ISBN 978-88-548-5153-5.

[10] P. J. Besl, N. D. McKay, "A Method for Registration of 3-D Shapes," IEEE Transactions on Pattern Analysis and Machine Intelligence, Vol. 14 (2), 1992, pp. 239-256.

[11] S. Rusinkiewicz, M. Levoy, "Efficient Variants of the ICP Algorithm", in Proc. Of Third International Conference on 3-D Digital Imaging and Modeling, 2001, pp. 145-152.

[12] S.J. Owen, "A Survey of Unstructured Mesh Generation Technology", Proc. of 7th International Meshing Roundtable, Oct. 26-28, 1998, Dearborn, Michigan, USA, pp. 239-267.

[13] W. Boehler, M. Bordas Vincent, A. Marbs, "Investigating laser scanner accuracy" in ISPRS archives, vol. XXXIV, Part5/c15, Antalya, 2003, pp. 696 - 701.

[14] L. Cipriani, F. Fantini, "Structure from Motion digital models to develop a cognitive system of the porticoes in Bologna", in Drawing. Ideas. Images. n. 50, 2015, pp. 70-81

[15] A. Angelini, G.. Capriotti Vittozzi, M. Baldi, The high official Harkhuf and the inscriptions of his tomb in Aswan (Egypt). An integrated methodological approach, in S. Grassini, A. Santoriello, (eds) The e-Journal of the International Measurement Confederation (IMEKO) Acta Imeko, Vol. 5 (2), 2016, pp. 71-79.

[16] G. Verhoeven, Taking Computer Vision Aloft - Archaeological Three-dimensional Reconstructions from Aerial Photographs with Photoscan, Arcaheological Prospection, 18, 2011, pp. 67-73.

[17] F. Nex, F. Rinaudo, "Multi-image matching: an "old and new" photogrammetric answer to Lidar techniques", in ISPRS archives, vol. XXXVII, Part B5, WG V/3, Beijing, 2008, pp. 621 $-626$

[18] A. Angelini, R. Gabrielli, C. Chiefari, C. Giorgi, B. Landini, "Innovative Methodology applied to the preventive excavation of new metro line C. The experimentation of La Spezia road Lodi Nord Square Station - in Rome", in Proc. of Istanbul Congress 2011 on the 5th International Congress on Science and Technology for the Safeguard of Cultural Heritage in the Mediterranean Basin, Vol. I, Rome, 2012, pp. 260-268. - ISBN 978-88-905639-8-0.

[19] M. Martone, Il valore dell'acqua nel patrimonio dei beni culturali attraverso la lettura di alcuni episodi architettonici, urbani e territoriali. Acquedotti e fontane a Roma dal XVI al XIX secolo, Aracne editrice, Roma, 2015, ISBN 978-88-548-9088-6

[20] A. Angelini, "Architettura Rupestre. Problemi metodologici di rappresentazione", in Carlevaris L. (a cura di), Linee di ricerca nell'area del Disegno 4. Contributi delle tesi di dottorato. XIII Congresso UID Firenze, Settembre, 2016, pp. 145-148 ISBN 978-88-6975-148-6

[21] R. Gabrielli, B. Landini, N. Amico, A. Angelini, R. Franchi, L. Menci, "The ancient drainage system of Petra: analysis and restoration for cultural heritage conservation. Methodologies applied to the conservation of the monumental Palace Tomb", in Proc. $4^{\text {th }}$ International Congress on Science and Technology for the Safeguard of Cultural Heritage in the Mediterranean Basin, vol. II, Roma, 2010, pp. 336-341

[22] J. S. McKenzie, The Architecture of Petra, Oxford, 1990, ISBN 1-84217-164-X

[23] F. Zayadine, Ph. Hottier, "Relevé photogrammétrique à Pétra", in ADAJ, XXI, 1976, pp. 93-104.

[24] M. Docci, D. Maestri, Manuale di rilevamento architettonico e urbano, Editori Laterza, Roma, 2012, ISBN 978-88-420-9068-7. 